\title{
SEM/EDS observations of impurities in polar ice: artifacts or not?
}

\author{
IAN BAKER, DANIEL CULLEN \\ Thayer School of Engineering, Dartmouth College, Hanover, New Hampshire 03755-8000, U.S.A. \\ E-mail: ian.baker@dartmouth.edu
}

\begin{abstract}
A series of experiments was undertaken to determine the origin of filaments found in grain boundaries and impurity spots found in grain interiors of polar ice during observation in the scanning electron microscope. It is shown that although the filaments are artifacts, they demonstrate the presence of impurities segregated to the grain boundary planes. It is also demonstrated that the impurities observed in the grain interior reside there and were not transported from the grain boundaries during specimen preparation or observation.
\end{abstract}

\section{INTRODUGTION}

In a number of recent papers (Cullen and Baker, 2000, 2001, 2002; Baker and Cullen, 2002; Iliescu and others, 2002; Baker and others, in press; Obbard and others, in press), we have used secondary electron (SE) imaging and energy-dispersive (X-ray) spectroscopy (EDS) in a low-vacuum scan- ning electron microscope (LVSEM) to examine the types and microstructural locations of impurities in polar ice-core specimens held at $158 \mathrm{~K}$. Specimen preparation involved shaving the surface flat in a cold room at $253 \mathrm{~K}$ and then allowing the ice to sublimate in the LVSEM at temperatures of $158-213 \mathrm{~K}$. The sublimation caused the impurities to be concentrated, after which the elements present could be

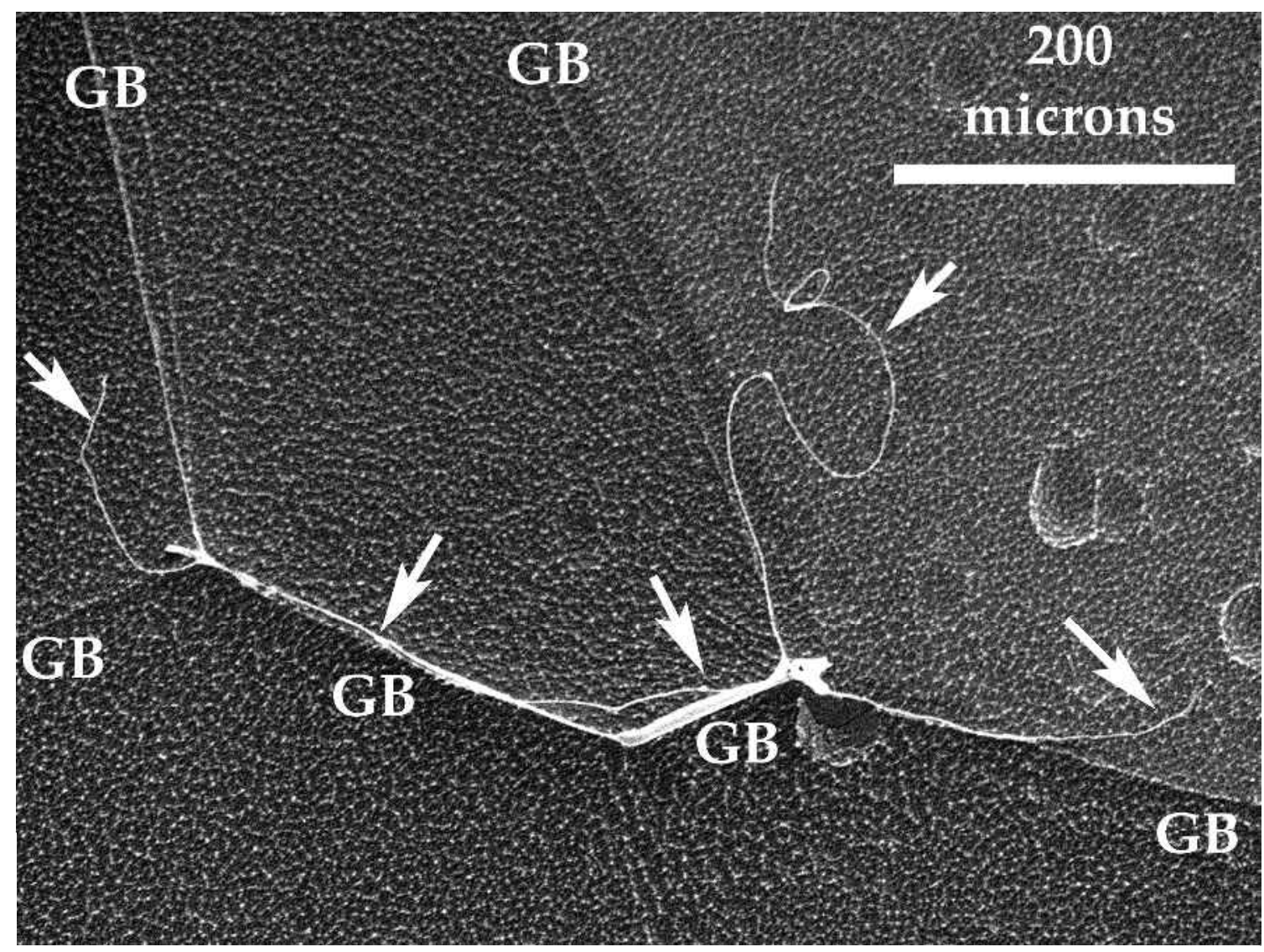

Fig. 1. SE image showing NaCl filaments (arrowed) which arose from the grain boundaries (GB) in $214 \mathrm{~m}$ GISP2 ice after 1 hour at $253 \mathrm{~K}$. Note that some of the filaments are no longer fully attached to the grain boundaries since they move due to heating from the electron beam. From Cullen and Baker (2000). 


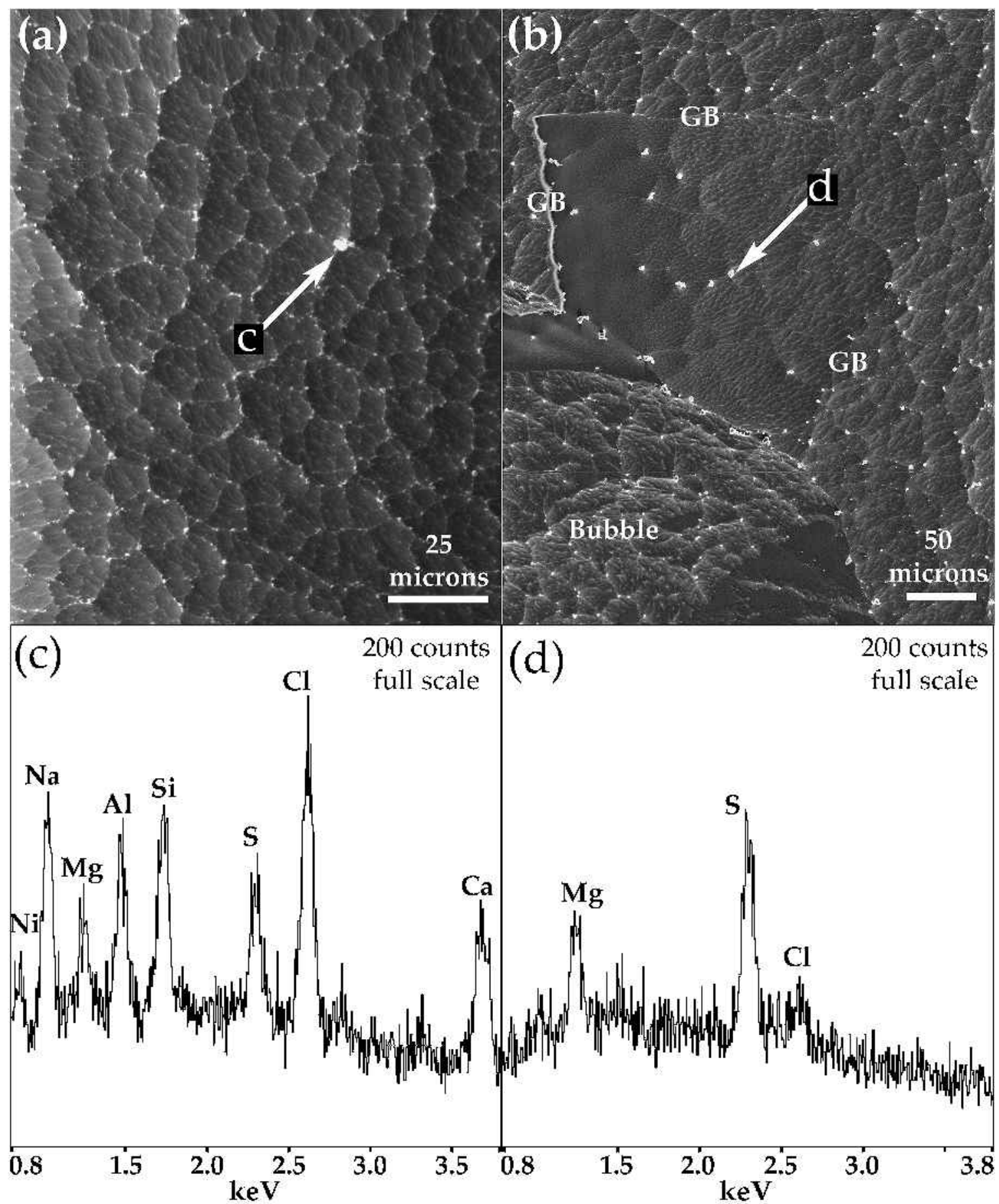

Fig. 2. ( $a, b)$ SE images showing an inclusion ( $a$ ) and white spots ( $b$ ) at the apexes of facets in $700 \mathrm{~m}$ Byrd Station ice after 20 and 75 min, respectively, at $173 \mathrm{~K} .(c, d)$ EDS spectra from the inclusion (c) and impurity spot $(d)$. The spectrum in $(c)$ is typical of that from inclusions, in that it contains Al and Si and several other elements: Si and Al are not typically observed in X-ray spectra from impurity white spots. Inclusions are typically larger than impurity spots: note the scale change between $(a)$ and $(b)$.

identified using EDS. It is worth noting that Barnes and others $(2002 \mathrm{a}, \mathrm{b})$ have used essentially the same technique to examine ice from a few depths at both Dome $\mathrm{C}$ and Dronning Maud Land in Antarctica, and from the Greenland Icecore Project.

Two significant observations have been made with this technique. First, filaments, consisting of $\mathrm{Na}$ and $\mathrm{Cl}$ in Greenland Ice Sheet Project 2 (GISP2) ice, and $\mathrm{Mg}$ and $\mathrm{S}$ in Byrd Station (Antarctica) ice, are present along most grain boundaries (Fig. 1). Second, contrary to some previous suggestions (Mulvaney and others, 1988; Wolff and others, 1988; Fukazawa and others, 1998), impurities are located throughout the grain interiors both in the lattice (Fig. 2a) and in inclusions (Fig. 2b) in GISP2 ice and Byrd Station ice. These observations have significance for understanding the mechanical and the electrical properties of ice (Paren and Walker, 1971; Wolff and Paren, 1984) and possibly for considerations of the post-depositional movement of impurities in polar ice (Rempel and others, 2001). However, it is pertinent to question whether these observations are artifacts of either the specimen preparation or observation methods, or whether they give us a true picture of the impurity locations in ice. In particular, we can ask: 

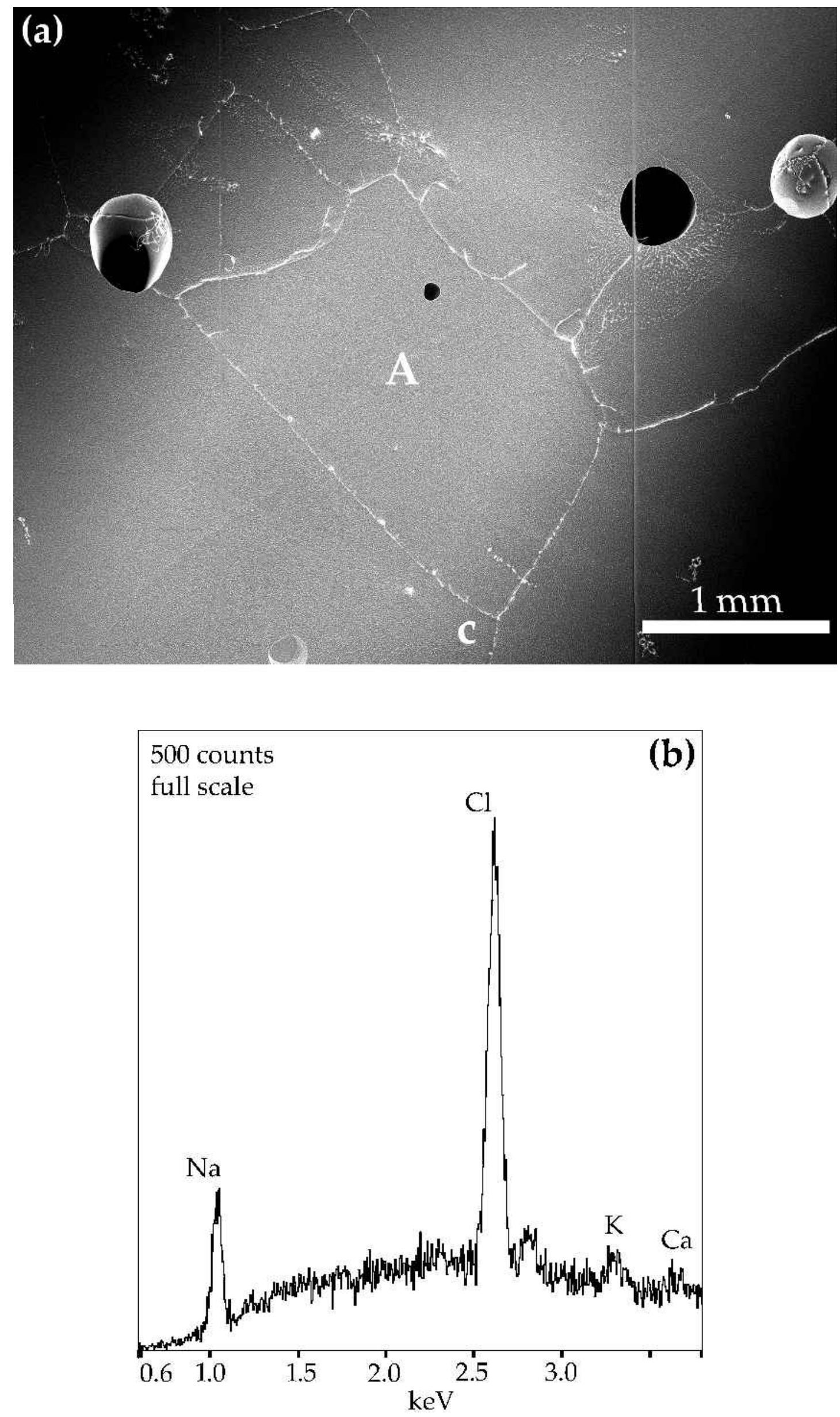

Fig. 3. Continued overleaf. 


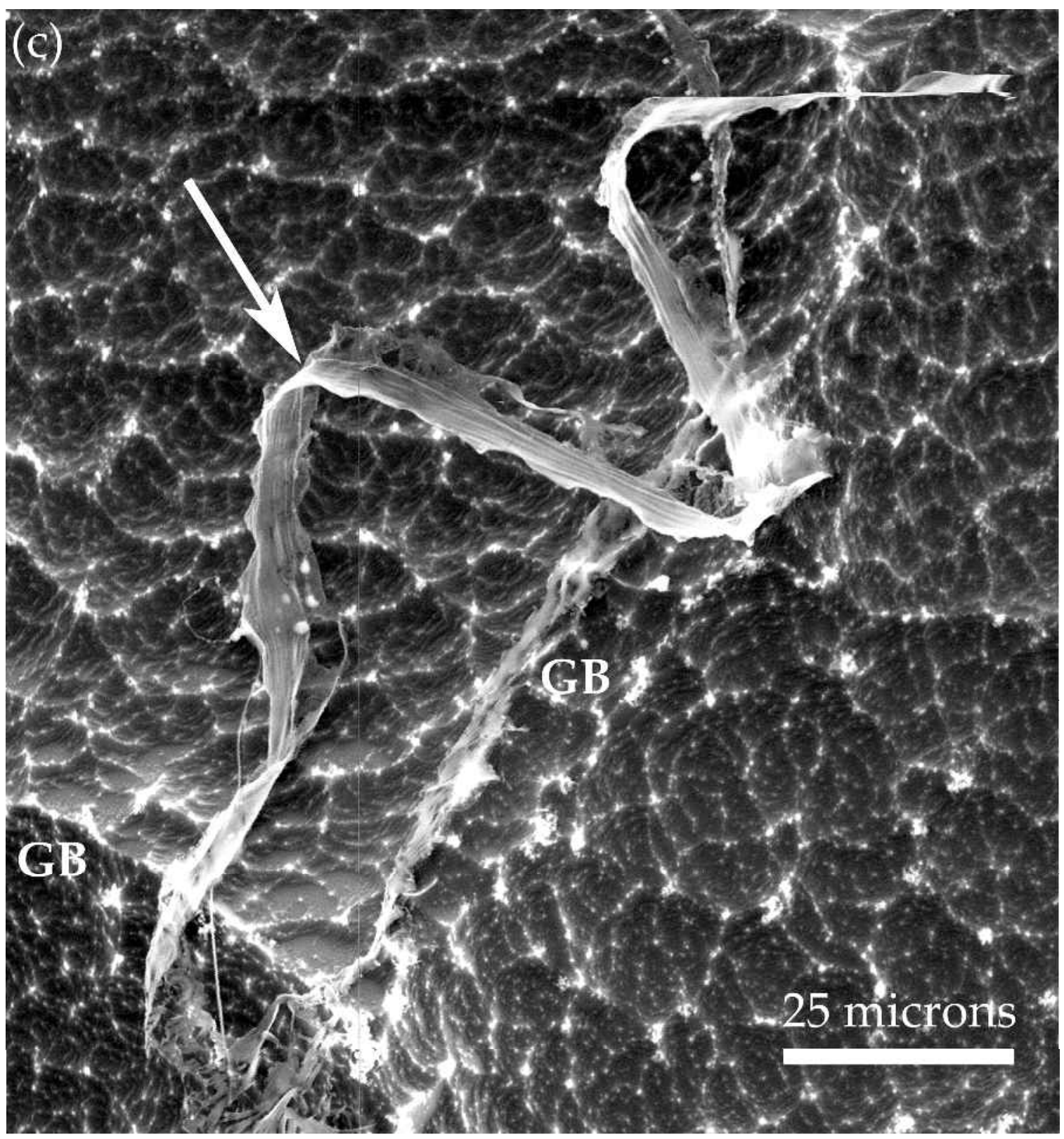

Fig. 3. (a) SE image after sublimation for 20 min at $183 \mathrm{~K}$ in the SEM (ice sublimated is approximately $0.1 \mathrm{~mm}$ ); (b) typical $X$-ray spectrum from the grain boundary; (c) SE image of ribbon-like $\mathrm{NaCl}$ filament (arrowed) from grain boundary (GB) indicated in (a) after sublimation for $\sim 40$ min at $183 \mathrm{~K}$ (ice sublimated is approximately $0.15 \mathrm{~mm}$ ).

1. Do the $\mathrm{NaCl}$ filaments present in the grain boundaries in GISP2 ice form in situ, or are they frozen water veins?

2. If the filaments form in situ, does the specimen preparation at $253 \mathrm{~K}$ spread the impurity-water eutectic films at the grain boundaries throughout the ice?

This paper attempts to answer these two questions.

\section{ORIGIN OF THE FILAMENTS}

Water veins exist along the triple junctions in high-purity ice close to its melting point (Steinemann, 1957; Ketcham and Hobbs, 1969; Nye and Frank, 1973). Dissolved impurities increase the diameters of the water veins and decrease their freezing temperatures (Mader, 1992). Thus, an obvious question regarding our observations is: are the filaments frozen impurity-containing water veins that remain after the ice has sublimated away in the SEM? This seems unlikely since we know the positions of both the triple junctions and the grain boundaries from optical microscope observation of each specimen before SEM examination, and filaments have been found along grain boundaries in which there were no nearby triple junctions from which they could have originated. Further, it is very unlikely that we could section horizontally through several triple junctions simultaneously to produce images such as that shown in Figure 1 (Cullen and Baker, 2000).

In order to investigate this further, an ice-core specimen from $150 \mathrm{~m}$ depth at GISP2 was examined after it was shaved to a thickness of $0.2 \mathrm{~mm}$. The average grain-size in the ice, determined using the linear intercept method, is $2.6 \mathrm{~mm}$. Thus, the specimen is significantly less than one grain diameter thick, and no obvious (non-vertical) triple junctions, from which frozen water veins could be produced, were observed. Figure 3a shows a SE image of a typical 1-2 mm grain (labeled "A") from this specimen. A representative X-ray spectrum from the grain boundary (Fig. 3b) shows largely $\mathrm{Na}$ and $\mathrm{Cl}$, 


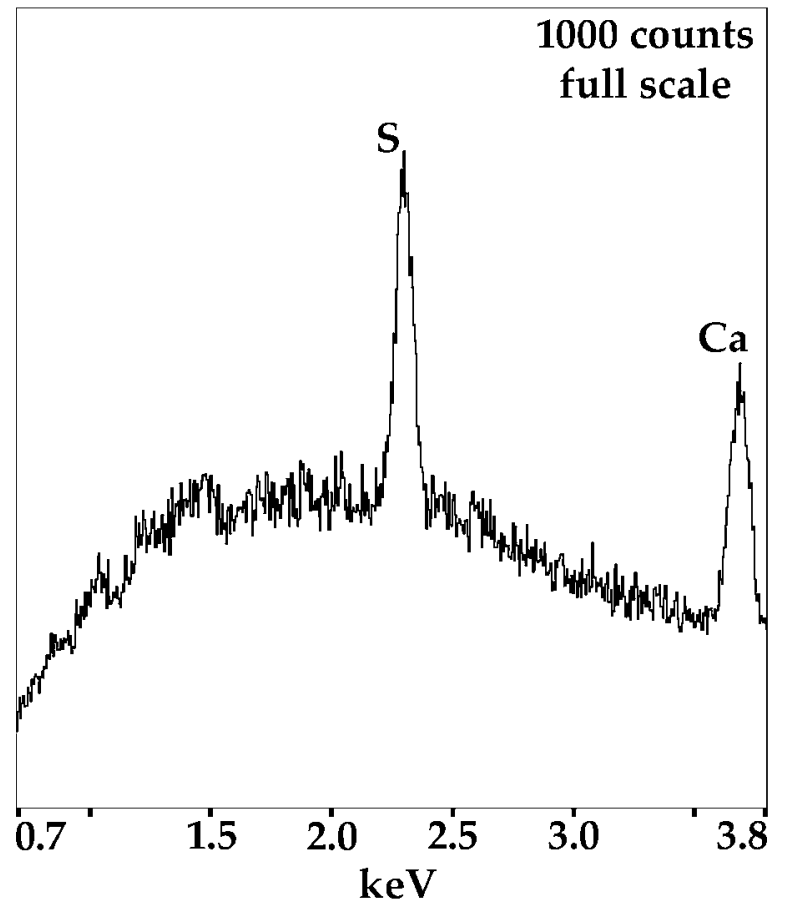

Fig. 4. X-ray spectra from impurities in an ice specimen from $1504 \mathrm{~m}$ Byrd Station ice after 15 min at $183 \mathrm{~K}$. The grain boundaries were removed prior to specimen preparation to preclude any possible impurity migration from the grain boundaries.

with small amounts of $\mathrm{K}$ and $\mathrm{Ca}$. Figure $3 \mathrm{c}$ shows a ribbon-like $\mathrm{NaCl}$ filament which "grew" out of the grain boundary during sublimation of the specimen in the SEM for $40 \mathrm{~min}$ at $183 \mathrm{~K}$. An X-ray spectrum from the filament again showed that it contained $\mathrm{Na}$ and $\mathrm{Cl}$. It was quite clear that this filament came from the grain boundary and that there was no triple junction from which it could have emerged.

Thus, it appears that formation of the grain-boundary filaments occurs as a result of the preferential sublimation of the ice that surrounds the impurities, which had segregated to the grain boundary prior to examination. The examination temperature in the SEM was well below the eutectic temperature of the $\mathrm{H}_{2} \mathrm{O}$-impurity systems for the observed impurities, and it is therefore likely that the filaments are hydrated ${ }^{1}$ salts, which coalesced (to reduce surface energy) after the surrounding ice sublimated away.

Thus, it appears that the filaments are artifacts. However, they indicate the presence of water-impurity eutectics at the grain boundary.

\section{DO IMPURITIES EXIST WITHIN GRAINS?}

If, as indicated above, a water- $\mathrm{NaCl}$ eutectic exists at the grain boundaries of GISP2 ice, then one concern is that specimen preparation at $253 \mathrm{~K}$ could have spread the impurities over the grains since the eutectic temperature is $\sim 250 \mathrm{~K}$, i.e. there would have been a liquid film at the grain boundaries (personal communication from A. Rempel, 2001). To examine whether specimen preparation introduced impurities

${ }^{1}$ Oxygen is always observed on the spectra since the electron interaction volume is greater than the filament size. Hydrogen cannot be detected with EDS.

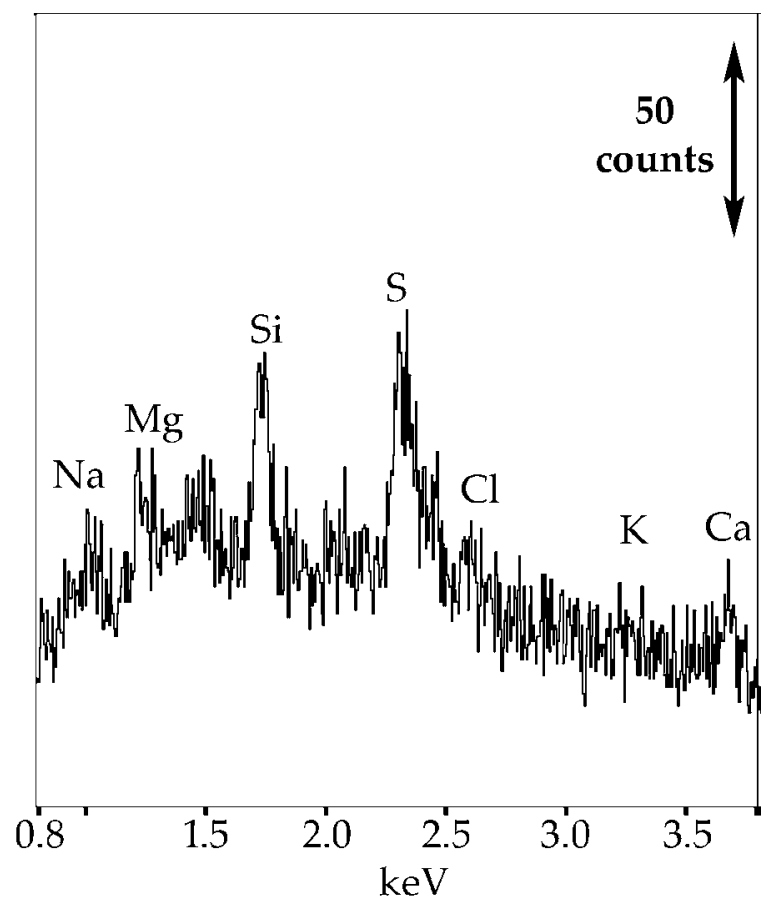

Fig. 5. EDS spectrum from an impurity spot in a $1102 \mathrm{~m}$ Byrd Station ice specimen shaved under liquid nitrogen. Sublimation time is 105 min at $173 \mathrm{~K}$ (ice sublimated is approximately $0.4 \mathrm{~mm}$ ).

into the grains, several experiments, as outlined below, were performed.

1. A specimen was shaved in one direction only, with the blade being cleaned after each pass. If the impurities were spread into the grain from the grain boundary, then a higher concentration of impurities would be observed in the grain shaved after the grain boundary. Experimentally, it was found that there was no evidence of more impurities in the grain on one side of the grain boundary than on the other.

2. All the grain boundary regions were cut off a single large grain before the surface was shaved and examined in the SEM. Impurity spots were still observed in the grain interiors (see X-ray spectrum in Fig. 4), even though no grain boundary films were present.

3. A specimen was shaved under liquid nitrogen, when all water-impurity eutectics would be frozen and immediately placed in the SEM. Upon SEM examination at $173 \mathrm{~K}$, impurity spots were found straightaway on the ice. Although the spots could immediately be seen, they had to "grow" before the EDS system could detect the impurities present, hence the $105 \mathrm{~min}$ sublimation indicated in Figure 5. It is worth noting that specimen preparation was not routinely performed under liquid nitrogen since the specimen is much harder at this temperature and hence is much more difficult to shave.

4. A specimen was cleaved under liquid nitrogen and, after sublimation in the SEM, impurities could still clearly be observed on the cleaved surface within the grains (see Fig. 6).

5. Ion chromatography was performed on melt from pairs of large-grained specimens from Byrd Station and GISP2. In each pair, one specimen had the grain boundary region removed and the other was analyzed with the 

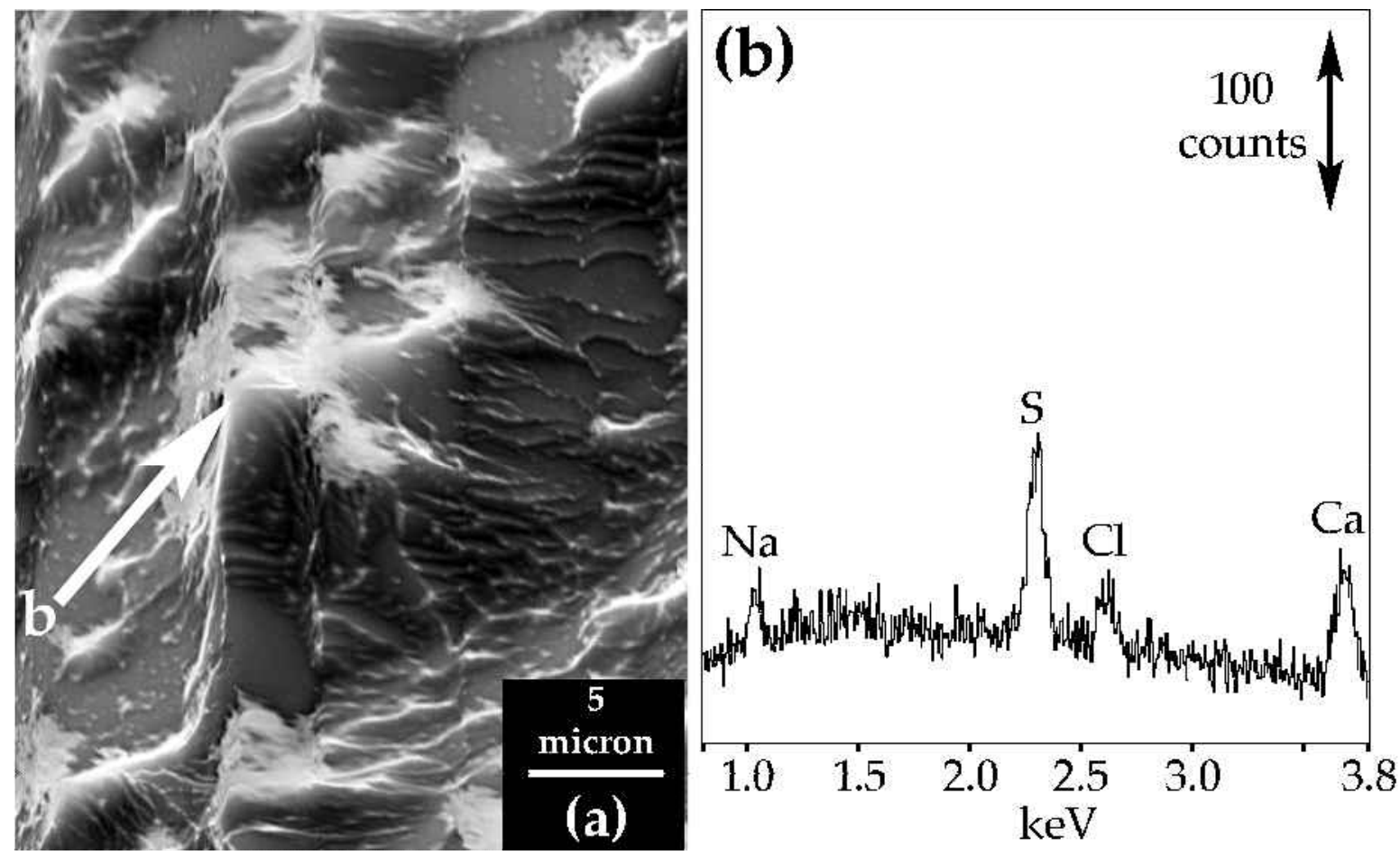

Fig. 6. (a) SE image of $1102 \mathrm{~m}$ Byrd Station ice cleaved under liquid nitrogen, after 190 min at $173 \mathrm{~K}$ in the SEM; (b) X-ray spectrum from the point indicated within the grain (ice sublimated is approximately $0.7 \mathrm{~mm}$ ).

grain boundaries intact. The results (Table 1) showed that while the specimens which contained grain boundaries generally had slightly higher impurity concentrations than the grain interiors, indicating that there was some concentration of impurities in the grain boundary region, the grain interiors contained comparable impurity levels.

It is also worth noting that for Byrd Station ice, where EDS identified mostly $\mathrm{Mg}$ and $\mathrm{S}$ at the grain boundaries, the specimen preparation temperature was below the $\mathrm{MgSO}_{4}-$ water eutectic temperature of $\sim 270 \mathrm{~K}$. Hence, no liquid film would be present to spread $\mathrm{Mg}$ and $\mathrm{S}$ over the grain interiors.

We also addressed the concern that the impurities arose in the grain interior by diffusion from the grain boundary during examination (Rempel and others, 2001) through the following experiments and observations:

(i) In (3) above, we noted that impurity spots could immediately be observed on the specimen surface after shaving at liquid-nitrogen temperatures and examination in the SEM at $158 \mathrm{~K}$ (again, the impurity spots had to "grow" before the impurities could be detected), suggesting that no diffusion of impurities was necessary to form them.

(ii) We examined the possibility that vapor transport could produce the impurities in the grain interior, by placing a specimen containing $\sim 1 \mathrm{ppm} \mathrm{H}_{2} \mathrm{SO}_{4}$ next to a high-purity ice specimen in the SEM, and examined whether impurity spots formed on the surface of the undoped ice. They did not.

(iii) In specimens cleaved under liquid nitrogen and examined immediately in the SEM, impurity spots were immediately present, although, as noted above, they had to "grow" before the EDS system could detect them, indicating that the impurities were present in the lattice.

(iv) Many elements were detected in impurity spots in grain interiors, while the grain boundaries in the GISP2 ice contained largely $\mathrm{Na}$ and $\mathrm{Cl}$ and those in Byrd Station

Table 1. Soluble ion concentrations (in ppb) in ice from Byrd Station and GISP2 measured by ion chromatography

\begin{tabular}{|c|c|c|c|c|c|c|c|c|c|c|c|}
\hline Location & $\begin{array}{c}\text { Depth } \\
\text { m }\end{array}$ & Worgi & $\begin{array}{c}\text { Grain-size } \\
\mathrm{mm}\end{array}$ & $\mathrm{Na}$ & $\mathrm{NH}_{4}$ & $\kappa$ & $M g$ & $\mathrm{Ca}$ & $\mathrm{Cl}$ & $\mathrm{NO}_{3}$ & $\mathrm{SO}_{4}$ \\
\hline GISP2 & 2950 & W & 60 & 158 & 11 & 20 & 14 & 28 & 269 & 68 & 61 \\
\hline GISP2 & 2950 & gi & 60 & 67 & 5 & 13 & 6 & 13 & 113 & 52 & 40 \\
\hline Byrd & 1992 & $\mathrm{~W}$ & 50 & 92 & 9 & 34 & 7 & 28 & 148 & 63 & 38 \\
\hline Byrd & 1992 & gi & 50 & 76 & 6 & 22 & 6 & 22 & 120 & 68 & 40 \\
\hline Byrd & 2090 & $\mathrm{~W}$ & 80 & 52 & 2 & 7 & 8 & 9 & 94 & 45 & 50 \\
\hline Byrd & 2090 & gi & 80 & 50 & 4 & 8 & 5 & 17 & 91 & 51 & 33 \\
\hline
\end{tabular}

Notes: "gi" refers to specimens in which the grain boundaries were removed prior to measurement and, thus, only the grain interior concentrations were measured."W" refers to specimens that contained both grain boundaries and grain interiors. The grain-sizes of the GISP2 and Byrd Station ice are from Gow and others (1997) and Gow and Williamson (1976), respectively. 
ice contained largely $\mathrm{Mg}$ and $\mathrm{S}$. Thus, the impurities within the grains could not all come from the grain boundaries.

Therefore, our observations indicate that the impurity spots in the grain interiors arise from impurities within the grains and are not artifacts. It is not wholly clear whether these impurities are present as precipitates or solutes (or a combination of both). However, it is worth noting that the longer a specimen was allowed to sublimate, the larger the white spots became, and the more likely the spots were to contain detectable impurities (since larger spots provide a larger interaction volume for X-ray production, which occurs from a region of the order of $1 \mu \mathrm{m}$ in diameter). Thus, one possibility is that some impurities were present as precipitates and other impurities coalesced on them, moving there by localized surface diffusion.

\section{GONGLUSIONS}

1. Filaments observed in the grain boundaries of polar ice are artifacts formed during SEM observation by sublimation of the surrounding ice. The filaments show that these impurities are concentrated in the grain boundary plane.

2. Impurities observed in the grain interiors are not artifacts from specimen preparation or observation. However, it is unclear whether these impurities are all originally in solution or whether some are present as precipitates.

\section{ACKNOWLEDGEMENTS}

This research was supported by the U.S. National Science Foundation grants OPP-9980379 and OPP-0221120 and Army Research Office (ARO) grant DAAD 19-00-1-0444. The ARO provided funds for the SEM/EDS through grants DAAH 04-96-1-0292 and DAAD 19-99-10068. M. Twickler is gratefully acknowledged for use of the ion chromatography facility at the Earth, Oceans, and Space Institute at the University of New Hampshire. E. Wolff made useful comments as a referee. S. J. Jones was the Scientific Editor.

\section{REFERENGES}

Baker, I. and D. Cullen. 2002. The structure and chemistry of $94 \mathrm{~m}$ Greenland Ice Sheet Project 2 ice. Ann. Glaciol., 35, 224-230.

Baker, I., D. Cullen, D. Iliescu and R. Obbard. In press. Scanning electron microscopy of natural ice. In Proceedings of the Mike Meshii Symposium. Warrendale, PA, The Metals, Minerals and Materials Society.

Barnes, P. R. F., R. Mulvaney, K. Robinson and E.W. Wolff. 2002a. Observations of polar ice from the Holocene and the glacial period using the scanning electron microscope. Ann. Glaciol., 35, 559-566.

Barnes, P. R. F., R. Mulvaney, E. W. Wolff and K. Robinson. 2002b. A technique for the examination of polar ice using the scanning electron microscope. F. Microsc., 205(2), 118-124.

Cullen, D. and I. Baker. 2000. Correspondence. The chemistry of grain boundaries in Greenland ice. F. Glaciol., 46(155), 703-706.

Cullen, D. and I. Baker. 2001. Observation of impurities in ice. Microscopy Res. Technique, 55, 198-207.

Cullen, D. and I. Baker. 2002. Observation of sulfate crystallites in Vostok accretion ice. Materials Characterization, 48(4), 263-269.

Fukazawa, H., K. Sugiyama, S. Mae, H. Narita and T. Hondoh. 1998. Acid ions at triple junction of Antarctic ice observed by Raman scattering. Geophys. Res. Lett., 25(15), 2845-2848.

Gow, A. J. and T. Williamson. 1976. Rheological implications of the internal structure and crystal fabrics of the West Antarctic ice sheet as revealed by deep core drilling at Byrd Station. Geol. Soc. Am. Bull., 87(12), 1665-1677.

Gow, A. J. and 6 others. 1997. Physical and structural properties of the Greenland Ice Sheet Project 2 ice cores: a review. 7. Geophys. Res., 102(C12), 26,559-26,575.

Iliescu, D., I. Baker and D. Cullen. 2002. Preliminary microstructural and microchemical observations of pond and river accretion ice. Cold Reg. Sci. Technol., 35(2), 81-99.

Ketcham, W. M. and P.V. Hobbs. 1969. An experimental determination of the surface energies of ice. Philos. Mag., 19(162), 1161-1173.

Mader, H. M. 1992. The thermal behaviour of the water-vein system in polycrystalline ice. F. Glaciol., 38(130), 359-374.

Mulvaney, R., E.W. Wolff and K. Oates. 1988. Sulphuric acid at grain boundaries in Antarctic ice. Nature, 331(6153), 247-249.

Nye, J. F. and F. C. Frank. 1973. Hydrology of the intergranular veins in a temperate glacier. International Association of Scientific Hydrology Publication 95 (Symposium at Cambridge 1969-Hydrology of Glaciers), 157-161.

Obbard, R., D. Iliescu, D. Cullen and I. Baker. In press. SEM/EDS comparison of polar and seasonal temperate ice. Microsc. Res. Techn.

Paren, J. G. and J. C. F. Walker. 1971. Influence of limited solubility on the electrical and mechanical properties of ice. Nature, 230(12), 77-79.

Rempel, A. W., E. D. Waddington, J. S. Wettlaufer and M. G. Worster. 2001. Possible displacement of the climate signal in ancient ice by premelting and anomalous diffusion. Nature, 411 (6837), 568-571.

Steinemann, A. 1957. Dielektrische Eigenschaften von Eiskristallen II. Teil Dielektrische Untersuchungen an Eiskristallen mit Eingelagerten Fremdatomen. Helv. Phys. Acta, 30, 553-610.

Wolff, E.W. and J. G. Paren. 1984. A two-phase model of electrical conduction in polar ice sheets. f. Geophys. Res., 89(B11), 9433-9438.

Wolff, E. W., R. Mulvaney and K. Oates. 1988. The location of impurities in Antarctic ice. Ann. Glaciol., 11, 194-197. 